\title{
FELSEFİ BAĞLAMDA YAPAY ZEKÂ VE 2025 SENDROMU
}

\section{Artificial Intelligence in the Philosophical Context and the 2025 Syndrome}

\section{Süleyman DÖNMEZ*}

Makale Bilgileri

\begin{tabular}{cc}
\hline Geliş Tarihi: & 18.02 .2020 \\
Kabul Tarihi: & 19.11 .2020 \\
Yayın Tarihi: & 25.12 .2020
\end{tabular}

\section{Özet}

Yapay zekâ, insanların yerine geçmek için değil, insan yeteneklerini ve katkılarını önemli ölçüde geliştirebilmek umuduyla tasarlanmıştır. Yapay zekânın insan yaşamının bir parçası hâline gelmesiyle de sanal bir gerçekliğin içinde insanın kaybolmasından çok artırılmış bir gerçeklik ile insan yaşamının standardının yükseltilmesi hedeflenmiştir. Ancak yapay zekânın yapabilecekleri fark edildikçe bu hedef, bir dizi endişeyi de beraberinde getirmektedir. Zira yapay zekânın hareket alanı bir karma gerçekliğe kaymaktadır.

Günümüzde yapay zekâ, yaşamın içinde çok yönlü olarak kendini göstermektedir. Öyle ki, insanların sorunlarını daha hızlı bir şekilde anlamak ve daha verimli cevaplar vermek için yapay zekâ işbaşındadır. Dahası zamanlamayı iyileştirmek için büyük kullanıcı tanımlı veri kümelerinden kritik bilgileri çekmek için yapay zekâdan yararlanılmaktadır.

İnsanlar yapay zekâya karşı duydukları korkularını dile getirdiğinde, genellikle kontrolden çıkmış insansı robotları hayal etmektedir. Bazen de geçmişe özgü benzetmelerle sanal dünyada gözetlenme kaygısı taşınmaktadır. En çok korkmamı gereken şey yapay zekânın kendi başına bize ne yapacağı değil, güç sahibi insanların bizi kontrol ve manipüle etmek adına yeni, bazen gizli bazen belirsiz ve beklenmeyen şekilde bunu nasıl kullanacaklarıdır. Yakın gelecekteki bağımsızlığımızı ve itibarımızı tehdit eden teknolojinin büyük kısmı veri ve dikkatimizi toplayıp reklamcı ve benzerlerine satan şirketler tarafindan geliştirilmektedir.

Yapay zekâ teknolojisi 2025'ten itibaren özellikle ticari yaşamı neredeyse bütünüyle kuşatacaktır. Ancak bu kuşatmanın sadece ticari boyutta kalmayacağını kestirmek zor değildir. Bu sebepten olsa gerek, birçok uzman 2025 sendromundan söz etmektedir.

Nedir bu 2025 yılında yaşanılacak olan sendrom? Bu sendromun yapay zekâ ile ilgisi nedir?

Yapay zekânın daha da yaygınlaşmasıyla beraber doğabilecek sorunlar kabaca iki farklı bağlamda tartışma zeminine çekilebilir.

İlki, yapay zekânın ne olduğundan çok nelere güç yetirebileceğidir. Meselenin bu yönü araştırıcısını olumlu ya da olumsuz anlamda bir dizi fantastik veya kurgusal çözümlemelere sevk edecektir. İkinci yön ise, mevcut hâli ile yapay zekânın ne getirip götürdüğüdür. Dolayısıyla 2025 itibariyle büyük oranda insan yaşamının içinde olacak olan yapay zekânın hangi sorunlara sebebiyet vereceğidir.

Yapay zekâ, internet reklamciliğından sonra gelen yeni bir teknoloji gibi görünse de durum farklıdır. Yepyeni bir süreçle karşı karşıyayız. Tamamen farklı bir dünyaya doğru yol almaktayız. Araştırma ve inceleme alanlarındaki kavrayışımızı hızlandırmaktadır. Fakat bu gelişmeler ciddi sıkintıları, riskleri de beraberinde getirmektedir.

\footnotetext{
* Prof. Dr., Akdeniz Üniversitesi/Edebiyat Fakültesi/Felsefe Bölümü/Türk-İslam Düşüncesi Tarihi Anabilim Dall, sdonmez@akdeniz.edu.tr, https://orcid.org/0000-0003-4251-6665
} 
$B u$ araştırmanın konusu teknik anlamda yapay zekânın ne olduğu değildir. Bu nedenle bu çalışmada yapay zekânın teknik yönü veya matematiği ile ilgili çok az bilgi verilmiştir.

Biz bu makalede hayatımızın ayrılmaz bir parçası hâline gelmeye başlayan yapay zekâ teknolojisiyle ilerde felsefì, dini ve iktisadî bakımdan ne tür değişmelerin açı̆̆a çıkabileceğini ve niçin yapay zekâ konusuna yönelmemiz gerektiğini tartışmaya açtık.

Anahtar Kavramlar: Yapay zekâ, ahlâk, akıllı robot, zihin, beyin.

\section{Giriș Yerine}

Huawei’nin dönüşümlü Yönetim Kurulu Başkanı Eric Xu'nun basına yansıyan şöyle bir beyanı var: "2025 yılı itibarıyla, kuruluşların çoğunluğunun dijital kullanımında bir patlama olacağını tahmin ediyoruz. O zamana kadar, kurumsal uygulamalarn yüzde 85'i buluta taşınacak, verilerin yüzde 80'i kullanıma açılacak ve şirketlerin yüzde 86'sı AI (Artificial Intelligence-Yapay Zekâ) deneyimi yaşayacak."1 Öyle görünüyor ki yapay zekâ teknolojisi 2025 'ten itibaren özellikle ticari yaşamı neredeyse bütünüyle kuşatacaktır. Ancak bu kuşatmanın sadece ticari boyutta kalmayacağını kestirmek zor değildir. Bu sebepten olsa gerek, birçok uzman 2025 sendromundan söz etmektedir. ${ }^{2}$ Uyarılarda bulmaktadırlar.

Nedir bu 2025 y1lında yaşanılacak olan sendrom? Bu sendromun yapay zekâ ile ilgisi nedir?

Yapay Zekâ (AI), "en basit ifadeyle, belli bir program dâhilinde tanımlanan görevleri yerine getirmek için insan zekâsını taklit eden ve topladıkları bilgilere göre yinelemeli olarak kendilerini iyileştirebilen sistemler veya makineler anlamına gelmektedir. Bir başka ifadeyle; esasen yapay zekâ, herhangi bir özel biçim veya işlevden ziyade süper güçlendirilmiş düşünce ve veri analizi yeteneği ve süreci ile ilgili bir teknolojidir.”3

Günümüzde yapay zekâ, yaşamın içinde çok yönlü olarak kendini göstermektedir. Öyle ki, "insanların sorunlarını daha hızlı bir şekilde anlamak ve daha verimli cevaplar vermek için yapay zekâ işbaşındadır. Dahası zamanlamayı iyileştirmek için büyük kullanıcı tanımlı veri kümelerinden kritik bilgileri çekmek için yapay zekâdan yararlanılmaktadır. Yapay zekâlar, öneri motorları, kullanıcıların izleme alışkanlıklarına göre TV programları için otomatik öneriler sunabilmektedir..." Artık yapay zekâlar, hedeflenenin ötesinde bir yola girerek asistanların, yardımcıların, hizmetçilerin, eşlerin, çocukların, kedilerin, köpeklerin yerini almaya başlamış görünmektedir. ${ }^{4}$

\footnotetext{
${ }^{1}$ Bkz.https://www.dunya.com/kose-yazisi/buyuk-firsatin-ortasindayiz-2025de-dijitalde-buyuk-patlamabekliyoruz/412943 (02.09.2020)

2 "Sendrom", "hastalık tablosu" olarak Türkçeleştirilmek istenen bir sözcüktür. Ancak "hastalık tablosu" tamlamasının anlam çağrışımı, henüz "özel bir bozukluğu gösteren ve bir arada görülen, tanıyı kolaylaştıran belirtilerin ve bulguların tümü " olarak açıklanan "sendrom" sözcüğünün Türkçesi olduğu Türkçede yeterince yaygınlaşmış değildir. Esasen daha çok tıp alanında özel bir bozukluğu gösteren ve bir arada görülen, teşhisi kolaylaştıran belirti ile bulguların tümünün adı olarak kullanılan sendrom kavramını, hastalık tablosu tamlaması ile Türkçeleştirmek çok da doğru görünmemektedir.

${ }^{3}$ https://edam.org.tr/teknoloji-uzerine-diyaloglar-7-yapay-zeka/ (07.02.2020)

${ }^{4}$ Krş. Harari, Y. Noah (2018), 21. Yüzyıl İçin 21 Ders, Türkçesi: Selin Sıral, 9. Baskı İstanbul: Kollektif Kitap, s. 3539.
} 
Yapay zekâ, aslında insanların yerine geçmek için değil, insan yeteneklerini ve katkılarını önemli ölçüde geliştirebilmek umuduyla tasarlanmıştır. Bu nedenle yapay zekânın insan yaşamının bir parçası hâline gelmesiyle sanal bir gerçekliğin (Virtual Reality) içinde insanın kaybolmasından çok artırılmış bir gerçeklik (Augmented Reality) ile insan yaşamının standardının yükseltilmesi hedeflenmiştir. Ancak yapay zekânın yapabilecekleri fark edildikçe bu hedef, bir dizi endişeyi de beraberinde getirmektedir. Zira yapay zekânın hareket alanı bir karma gerçekliğe kaymaktadır (Mixed Reality). ${ }^{5}$ İşte 2025 sendromu, yapay zekâ teknolojisindeki yeni gelişmeler sayesinde yapay zekânın özellikle de yapay zekâyla hareket eden insanın iş görürken daha da etkin olmaya başlamasıyla önümüzdeki yıllarda karşılaşılacak olan muhtemel sorunların tartışma alanına çekilmesidir.

Yapay zekânın daha da yaygınlaşmasıyla beraber doğabilecek sorunlar kabaca iki farklı bağlamda tartışma zeminine çekilebilir.

İlki, yapay zekânın ne olduğundan çok nelere güç yetirebileceğidir. Meselenin bu yönü araştırıcısını olumlu ya da olumsuz anlamda bir dizi fantastik veya kurgusal çözümlemelere sevk edecektir. Zaten, gerçekte insan zihni ile karşılaştırıldığında oldukça ilkel düzeyde kalan yapay zekâ teknolojisinin zihinlerde dünyayı ele geçiren çok fonksiyonel, insan benzeri robotlar olarak canlanmasının asıl sebebi de bu ucu açık durumdur. Bu hususta öne sürülen fikirler ise, esasen tamamen temelsiz değildir. Öyle ki, yapay zekâ gerçekten gün geçtikçe insana daha çok benzemektedir. Hatta bazı konularda, özellikle uzmanlık bakımından insandan daha bilgili, becerikli ve hızlıdır. ${ }^{6}$ Ama bu, ilk etapta yapay zekânın insanlık için büyük bir tehlike olacağı anlamına gelmemektedir. Zira henüz kontrol, insandadır. Makinaların insanın denetiminden kurtulup kurtulamayacağı ya da insanları kontrol edip edemeyeceği ise belirsizliğini korumaktadır. ${ }^{7}$

\footnotetext{
5 "AR + VR = MR: Sanal Gerçeklik (VR) ile hiç olmayan veya uzaklardaki yerlere gittik; Artırılmış Gerçeklik (AR) ile bulunduğumuz ortama veriler, bilgiler ve sanal etkileşim özellikleri kattık, şimdi ikisinin birleşimi olan Karma Gerçeklik (Mixed Reality) için hazırız." https://kurious.ku.edu.tr/teknolojinin-altin-cagi/ (07.09.2020)

6 "1950'lerden 1990'lara kadar geçen sürede, bilgisayarlar satrançta insanları geçemiyordu. Dünya tarihinin en iyi satranç oyuncusu olarak gösterilen ve günümüzde hala satranç deyince akla ilk gelen isim olan Garry Kasparov, IBM'in Deep Blue isimli satranç bilgisayarı ile kendisine meydan okumasını ve süper satranç bilgisayar Deep Blue ile satranç maçı yapmayı kabul etmişti. 1996 yılında yapılan ilk maçı kazanan Kasparov, bir bilgisayarın hiçbir zaman bir insandan daha zeki olamayacağı izlenimini bırakmıştı. Yapılan 6 setlik maçlar sonunda Kasparov Deep Blue'yu 4-2 yendi. IBM sonraki yıla kadar Deep Blue'yu, Deeper Blue olarak geliştirdi. 11 Mayıs 1997 tarihinde, Deeper Blue, dünyanın en iyi satranç oyuncusu Garry Kasparov’u yendi. Yine 6 setten oluşan bu maç sonucunda Deeper Blue Kasparov'u 2.5 a karş1 3.5 puanla yenmeyi başard1. Kasparov-Deeper Blue maçlarında Deeper Blue 3 dakikada 60 milyar hamleyi gözden geçirebiliyor, saniyede 200 milyon işlem yapabiliyordu. Kasparov 2. oyunun 37.Be4 hamlesinde Deeper Blue'ya insanlar tarafından müdahale edilerek yardım edildiğini iddia etti. Çünkü böyle bir durumda bir bilgisayarın 37.Qb6 hamlesini yaparak bir piyon kazanma eğiliminde olması bekleniyordu ve bu beklentisi pek çok satranç otoritesi tarafından da onaylandı. Fakat IBM bu iddiayı ve Kasparov'un yeniden maç önerisini reddederek Deep Blue projesini sona erdirdi." https://www.matematiksel.org/bir-yapay-zeka-ornegi-kasparov-deep-blue-gercegi/ (07.09.2020).

"İnternet devinin 2014 yılında satın aldığı İngiliz yapay zeka servisi DeepMind uzun süredir meme kanseri konusunda çalışma yapıyordu. Kadınlar arasında en yaygın görülen kanser türü olan meme kanseri ne yazık ki teşhisi en zor kanser türlerinden biri. Kadınlar için büyük risk oluşturan bu hastalığın erken teşhisi de hayati bir önem taşıyor. DeepMind'ın geliştirdiği ve hastanelerde denemeye soktuğu yeni yapay zekalı teşhis yönteminin, doktorlardan bile daha büyük oranda teşhis bașarısı yakaladığı ortaya çıktı. Meme kanserinde teşhis sürecini daha ucuz, daha pratik ve hızlı bir işleme dönüştürecek olan yapay zekalı muayene hata oranını da \%5 ile 9.5 arasında düşürmüş görünüyor.” https://www.cnnturk.com/teknoloji/yapay-zeka-ile-meme-kanseri-teshisi (07.09.2020).
}

${ }^{7}$ Bkz. Harari 2018: 37. 
İkinci yön ise, mevcut hâli ile yapay zekânın ne getirip götürdüğüdür. Dolayısıyla 2025 itibariyle büyük oranda insan yaşamının içinde olacak olan yapay zekânın hangi sorunlara sebebiyet vereceğidir. Öyle ki, yapay zekâ insanlığı ahlâktan, ekonomiye, bilimden sanata, felsefeden dine, hukuktan siyasete; kısaca hayatın her alanına sirayet edecek olan bir dizi mesele ile uğraşmak zorunda bırakacak görünmektedir. Bu durumda yapay zekânın insanlığa ne getirip ne götüreceği sorunu çok yönlü olarak tartışmaya açılmalıdır.

Bu makalede yapay zekâ meselesi yukarıda ifade edilen her iki bağlamda özetle teşrih masasına yatırılacaktır. Bizim burada kısaca dikkât çektiğimiz bu hususların daha geniş bir şekilde başka çalışmalarla farklı bağlamlarda ele alınması gerekmektedir.

\section{Yapay Zekâ İnsanlık İçin Büyük Bir Tehlike Mi?}

2018 tarihinde hayata gözlerini yuman ünlü astrofizikçi Stephen Hawking, 21. Yüzyılda yapay zekânın insandan daha zeki olacağını iddia etmişti. ${ }^{8}$ İnsandan daha zeki olan ve insanın kontrolünden çıkan bir yapay zekânın ciddi tehlike arz edebileceği açıktır. Ancak insanın kontrolünde insanlığın iyiliği için kullanıldığında ise büyük fayda sağlayacağı ifade edilebilir. Elbette buradaki tek ayırıcı nokta insanın yapay zekâyı denetleyebilmesi değildir. Denetimli kullanımın insanlığın faydasına dönük olması zorunluluğudur. Aksi takdirde yapay zekânın insanın denetiminde olmadan verebileceği zararın çok daha şiddetlisi insan tarafından yönlendirilen yapay zekâ ile verilebilir. Esasen bize göre asıl tehlike de budur. Bu nedenle yapay zekâ ve kullanımı ile ilgili gerekli hukukî düzenlemelerin acilen yapılması elzemdir. Hukukî anlamda zapturapt altına alınmış olan yapay zekâ kullanımı, insanlığın ve dünyamızın hayrına olabilir. Bu durumda yapay zekânın olası işgali karşısında duyulan endişeler yersiz görülebilir. Lakin yaşamın her alanına yayılan bir yapay zekâ sonunda -yapay zekâ ile ilgili her türlü düzenlemeler yapılmış olsa bile- insanın yaşam biçimi ne tür bir değişime uğrayacaktır?

Bize öyle gelmektedir ki, insan kendini anladığı ölçüde teknolojik olarak modellemek istemektedir. ${ }^{9}$ Yapay zekâ teknolojisi de zihnin ve beynin anlaş1labildiği oranda somutlaştırılmasıdır. Böylece insan, sanki bir taraftan kendini yaratmaya çalışmakta, diğer taraftan da gittikçe kendine benzeyen bu varlıkları kendine hizmet ettirmektedir. Âdeta insan çalışıp didinmeyi zeki makinalara devrederek bir yapay yeryüzü cenneti kurmanın peşine düşmüştür.

\footnotetext{
8 https://www.bbc.com/turkce/haberler/2014/12/141204_yapay_zeka_insanligin_sonu (07.09.2019)

9 “50 Soruda Yapay Zeka kitabının da yazarı, Boğaziçi Üniversitesi Bilgisayar Bilimleri öğretim üyesi, Prof. Dr. Cem Say ile konuştuk...

N.D: Çok soyut bir kavram olarak kalan bir tanım, yapay zeka nedir? Yapay zekanın mantığı nedir?

C.S: Yapay zekâ büyük bir proje aslında. İlk çıktığında bir mühendislik projesi olarak çıkıyor, bu kelimeleri seçmelerinin sebebi, o zamana kadar bilgisayarın yapamadığı, sadece insan zekâsına has görülen ișlerin tamamını bilgisayara da yaptırmak için kolları sıvama konulu bir toplantıyla başlıyor. İnsan beynini taklit ederek, insan beyni hangi problemi çözebiliyorsa, nasıl düşünüyorsa onun tıpatıp aynısını hatta mümkünse insanlardan daha hızlı, daha verimli, daha ucuza bilgisayarlara yaptırma projesi..." Bkz. https://edam.org.tr/teknolojiuzerine-diyaloglar-7-yapay-zeka/ (07.09.2020)
} 
Yapay zekâ gerçekten de birçok sektörde hızla insanın yerini almaktadır. Artık yapay zekâ fabrikada işçi, mühendis ${ }^{10}$; hastane de doktor, hemşire ${ }^{11}$; üniversitede hoca olabilecek bilgi donanımı ile becerisine sahiptir. Dahası insandan çok daha becerikli ve verimlidir. $\mathrm{Bu}$ durumda insanın yerine geçen ve insana hizmet eden bir yapay zekâ, insana dünyada cenneti kuracağını hayal ettirse de yapay zekâ ile işinden olan insanın aşından da olmayacağı belirsizdir. Yapay zekâ işsiz ve aşsız kalan insana aş verebilecek midir? Diyelim aş sorunu bir şekilde çözüldü. İşi gücü olmayan insan ne yapacaktır? Yiyen, içen, sevişen, gezen, dolaşan ya da dövüşen, tembel tembel oturan insanlar mı dolduracak dünyayı? Yoksa dünya felsefî, dinî sohbetler ile estetik, sanatsal, sportif meşgalelere dalan insanların yurduna mı dönüşecek?

Yapay zekânın hizmet ve üretim sektöründe insanı tamamen etkisiz hâle getirmeyeceği, her hâlükârda insana ihtiyaç duyulacağı öne sürülebilir. Dolayısıyla dünya cenneti inşasının bir kurgu olduğu iddia edilebilir. Bu iddia doğru da görünse, yapay zekânın birçok alanda insana göre daha çok tercih edileceği göz ardı edilemez bir gerçektir. Bunun anlamı, işsiz güçsüz kalan insanlar demektir. Aş meselesi çözülemediği müddetçe, yapay zekâ ile kurulmak istenen cennet çabası, dünyayı insanın cehennemine çevirecektir. Meselenin bir sendrom olarak değerlendirilmesinin sebebi de budur.

İnsanoğlu, yapay zekâ teknolojisinde gerçekten kendisini mi modellemektedir?

Bizce minval, öyle görünmektedir. Bu durumda insanın kendi ayarında bir yapay zekâ yapamaması, kendini yeterince çözemediğini göstermektedir. Zira açığa çıkan sonuç kendini anladığ ölçüdedir. Elbette insanoğlu henüz idrak ettiğini bütünüyle ve yetkin bir şekilde modelleyebilmiş değildir. Özellikle teknik yetersizlikler söz konusudur. Ama insan, büyük bir gayretle engelleri aşarak daha da ileriye gitmeye çalışmaktadır.

Diyelim ki, insan kendini tam anlamıyla çözdü. Acaba anladığı ve çözümlediği ölçüde kendine benzeyen bir yapay zekâ yapabilecek midir? Bir başka ifadeyle, insan kendinin, dahası kendisini aşan bir varlığın yaratıcısı olabilir mi? Metafizik veya teolojik bağlamda bu mümkün müdür?

Kendi sınırlı varoluşunu aşan bir varlık inşası, olsa olsa adına insan denen varlık tarafından denenebilir. Çünkü insan, boyundan büyük işlere kalkışma beceresine sahip bir varlıktır. Sınırları ve sınırlarını zorlayan bir yaratılışa sahiptir. İnsanın bu hadsiz ve hesapsız girişimi, sürekli başını ağrıtır. Onu sıkıntılı bir sürecin içine sokar. Bu nedenle kendi elleriyle zorlaştırdığ yaşam biçimini kolaylaştırmak için bir dizi çalışma yürütmek isterken, genelde farkında olmadan daha büyük sorunlara kapı aralar. Örnek vermek gerekirse, günümüzde adlî vakaların sayısı çok artmıştır. İnsanlar çeşitli sebeplerle hukukî kovuşturmaya uğramaktadır. Birçok kovuşturma ile soruşturmada işlerin kolaylaşması ve

\footnotetext{
10 Uygunoğlu, Tayfun ve Yurtcu, Şaban (2006), "Yapay Zekâ Tekniklerinin İnşaat Mühendisliği Problemlerinde Kullanımı" Teknolojik Araştırmalar: YTED 1 (1): 61 - 70

${ }^{11}$ DEMİRHAN, Ayşe; KILIÇ, Yusuf Alper; GÜLER, İnan (2010), "Tıpta Yapay Zekâ Uygulamaları", Yoğun Bakım Dergisi; 9 (1):31-41.
} 
hızlanması için özellikle Avrupa ile Amerika'da yapay zekâdan faydalanılmaktadır. ${ }^{12}$ İlk planda büyük bir kolaylık gibi görünen bu durum, bugün büyük bir skandala dönüşmüş görünmektedir. Çünkü Amerika Princeton Üniversite'sinden Dr. Aylin Çalışkan ve beraber çalıştı̆̆ grup, yapay zekâ programcılarının yaptıkları yazılımlara önyargılarını da aktardıklarını tespit ettiler. ${ }^{13}$

Yapılan çalışmalarda açığa çıktı ki, zencilerin yazdığı yapay zekâ programları beyazlara, beyazların yazdığı yapay zekâ programları ise zencilere daha fazla ceza kesmektedir. ${ }^{14}$ Önyarg1lı yapay zekâlar, adalet meselesini nasıl etkileyecektir?

Önyargılı bir yapay zekânın insana nazaran daha radikal bir önyarg1 ile işlem yapacağını kavramak zor değildir. Çünkü yapay zekâ programlandıktan sonra insanın gösterdiği değişkenliği göstermemektedir. İnsan zamana, mekâna göre farklı duygusal tepkiler verebilir. Unutur. Hatırlar. Ama yapay zekâ ne unutur ne de hatırlar. O öğretilmiş ve öğrenen bir makinadır. Onun keskin biliş tarzı telafisi mümkün olmayan sonuçlar üretebilir. Hukukî işlemlerde yapay zekâya güvenerek karar onaylayan hâkimler, şimdiye kadar acaba kaç insana hak etmediği cezayı kestiler? Amerikalılar şimdilerde bu sorunu gündeme getiriyorlar. Yapay zekâ insanların önyargılarını büyütebilir görünmektedir. ${ }^{15}$

Acaba insan ayarında bir yapay zekâ geliştirilebilir mi?

İnsanın hedefinin bu yönde olduğu sezilse de kanaatimizce, insan kendi standardında bir yapay zekâ geliştiremeyecektir. Çünkü insanın yapabildiği, idraki ile sınırlıdır. İnsan, kendini ise henüz tam olarak çözmüş değildir. İnsan hâlâ birçok yönüyle muammadır. Yapay zekâ ise karmaşık bir varlık olarak insan karşısında oldukça ilkel kalmaktadır. Öyle ki, yapay zekâ, hızına, bilgisine ve becerisine rağmen olasılık hesaplamalarına dayalı iş gören ve bu bağlamda karmaşıklaşan bir makineden ibarettir. Lakin buna rağmen, eğer şekil ile şemail açısından insandan ayrıştırılamaz hale getirilebilirse bir dizi toplumsal ve felsefî sorunla da karşı karşıya kalınacağı açıktır.

Ne demek istediğimizi biraz açalım.

Yapay zekâ teknolojisindeki muhtemel gelişmeler, zannımızca, insanın gerçek anlamda özgür bir varlık olduğunun açık bir kanıtı olacaktır. Çünkü insan birçok konuda olduğu gibi, yapay zekâ üretme işinde de fütursuz olacaktır. Sinırları zorlayarak insana benzeyen, ama muhtemelen insandan çok daha hoyrat ve yıkıcı makinalar üretecektir. Bu

\footnotetext{
12 Çağlar, Ersoy (2019), Robotlar, Yapay Zekâ ve Hukuk, 3. Baskı, İstanbul: On iki Levha Yayıncılık, s. 179.

${ }_{13}$ Metinler arasındaki ilişkileri inceleyen GloVe (Global Vectors for Word Representation) adlı sistem, insana dair tüm önyargıların, yapay sistemlerde de ortaya çıktığını keşfetti. Princeton Üniversitesi bilgisayar bilimleri dalında doktora yapan Aylin Çalışkan, "Verileri, Wikipedia ya da haber metinleri gibi tarafsız bir dile sahip olduğunu varsaydığımız kaynaklardan edinen yapay zekâ, tamamen insanların temel önyargılarını yansıtıyor" dedi. https://kurious.ku.edu.tr/haberler/yapay-zeka-zeki-ama-onyargili/ (07.09.2020)

${ }^{14} \mathrm{https}$ // robotic.legal/telif-hakki-yasalarinin-yapay-zekanin-dolayli-onyargi-sorununu-nasil-duzeltebilecegi/ (07.09.2020)

15 https://www.fortuneturkey.com/yapay-zekanin-onyargi-sorunu-54794 (07.09.2020)
} 
ise, insanlığ çok ciddî bir ahlâk sorunuyla yüzleşmek zorunda birakacaktır. ${ }^{16}$ Zira henüz hiçbir programcı adalet; insanlara, doğaya zarar vermemek, iyilik, aşk gibi anlamların bir makinada nasıl programlanabileceğini bilmemektedir. Bu durumda beşerin temel ahlâkî hususlarda ciddî zaafları olduğu gerçeğinden hareketle insanın iş halletmede kendisinden daha üstün bir yapay zekâ üreterek tehlikenin boyutunu daha da artırması, insanın ve evrenin geleceği adına akıl ile izan işi değildir.

Diğer taraftan iyi bir yapay zekâ üreterek insanı onun denetimine verilebileceği de pek makul görülmemektedir. Öyle ki, yapay zekâ etiği üzerine çalışan Yale Üniversitesi Disiplinlerarası Biyoetik Merkezi Etik Danışmanı ve Araştırmacı Öğretim Üyesi Wendell Wallach, ahlâklı akıllı robot üretme ilkelerinin işe yaramadığına dikkat çekmektedir. Wallach, kendi çocuklarımıza ahlâklı olmayı öğretememişken ahlâklı olmayı robotlara nası1 öğretilebileceğini sormaktadır. ${ }^{17}$ İnsan her ne kadar içinde yaşadığ 1 toplumun değer ve normlarına uygun olarak ahlâkı yaşıyor olsa da ${ }^{18}$, ahlâkın yalnızca birtakım kuralların ezberlenerek uygulandığı bir duyuş ile davranış olmadığının altı çizilmelidir.

Yapay zekâ, ismiyle müsemma, zeki görünmektedir. Lakin gerçekten akıllı mıdır? Akılsız, ama güçlü bir zekânın tahribatı tartışmasız yıkıcı olacaktır. Bu ifadedeki aklı "nous", zekâyı ise "logos" anlamında kullanıorum. Nous, selim kalbi, selim zevki ve selim aklı içeren gönle ya da cana tekabül eder. Logos, ise çıkara dayalı matematik düşünmeyi karşılar. Nous, öz, logos ise sözdür. Bu çerçevede yapay zekâ özsüz bir yapıdır. Sözden ibarettir. Söz, sadece dışı gösterir. Ahlâk ise, her ne kadar dışta görünse de, içte olanın dişa yansımasıdır. ${ }^{19}$ Çünkü ahlâk içte kurulur. Yapay zekânın insan gibi bir içe sahip olup olamayacağı ise meçhuldür.

Hâlihazırdaki yapay zekâlar içsizdir. Bu hâl, şekil şemail olarak özellikle insandan ayırt edilemez yapay zekâlar aramızda dolaşmaya başladığında sadece ahlâkî ve felsefî değil, ciddî teolojik (dinî) sorunları da gündeme taşıyacaktır. Mesela görünüşte insandan ayrıştırılamayan bir zeki robot, imamlık yapmaya kalkışırsa kılınan bu namazın hükmü ne olacaktır? Daha ziyade bilgiye dayalı seyreden mevcut fikhî ölçü dikkate alındığında liyakat açısından yapay zekâ, vasat bir insandan çok daha yeterli ve yetenekli görünmektedir. Yapay zekâ teknolojisi ilerledikçe onun bir insan olmadığı, dolayısıyla böyle bir durumu tartışmanın gereksiz olduğu söylemi, ilerde yaşanması muhtemel sorunlara bir çözüm üretmeyecektir. Öyle ki, ezberletilen kuralları düzgünce uygulayan ve kendisinin bir insan olduğunu, hissettiğini, üzüldüğünü dile getiren bir zeki robota, "sen insan değil, aptal bir robotsun, benim gibi duyuyor, üzülüyor olamazsın" demenin pratikte bir geçerliliği yoktur. Daha da ötesi günümüzde Fransa, Hollanda gibi Avrupa ile birçok Doğu ve Uzakdoğu

\footnotetext{
16 Topakkaya, Arslan ve Eyibaş, Yağmur (2019), "Yapay Zekâ ve Etik İlişkisi”, Felsefe Dünyas1, 70 (1), s. 95.

17 https:/ / khosann.com/ahlakli-robotlar-1-robotlar-etik-kararlar-alabilir-mi/ (07.09.2020)

18 Kaynak Iltar, Ekin (2019), Dijital Nesillerin Teknoloji Bağımlılı̆̆, Ankara: Nobel Yayınevi, s.258.

19 Daha geniş bilgi ve temellendirme için bkz. Dönmez, Süleyman (2015), Emanet Ahlâkı: Türk Ahlâk Felsefesine Giriş, Adana: Karahan Kitabevi, s. 23-32.
} 
ülkelerinde zeki robotların hizmet verdiği genelevler türemiştir. ${ }^{20}$ Birçok insan insanlarla değil robotlarla ilişkiyi tercih etmeye başlamış durumdalar. Robot ile cinsel temasa geçmenin hükmü nedir? Robotla evlenilebilir mi? Bir insan kaç robot alabilir? Yönelttiğim sualler, acil cevap beklemektedir. Diyanetçilerin, ilahiyatçıların bu yeni sektöre yaklaşımı nasıldir? 21

Unutulmamalıdır ki, hiçbir insan diğer bir insanın nasıl hissettiğini veya üzüldüğünü gerçekte bilemez. Sadece kendi hisleri üzerinden karşısındakini anlamaya çalışır ya da anladığını söyler. Neticede gelişmiş bir zeki robot da benzer bir duyuş yaşadığını iddia edebilir. İnsan tanrıca bir duyuşa ve bilişe sahip olmadan, üretilen yapay zekâlı bu zeki robotun gerçekte neyi hissettiğini ya da hissiz olduğunu bilme şansı kalmayabilir. Dolayısıyla tıpkı insan gibi düşünen, konuşan, duygusal tepkiler gösteren bir zeki robotinsan (siborg) kolonisi oluşabilir. Robot-insan, bilgi sahibi, lakin bilgisiyle irfana yükselememiş bir dünya varlığı olacaktır. Açığa çıkacak olan varlık, küresel, vahşi insan tipinin bir benzeri olabilir. Ama ondan daha hızlı, daha bilgili ve daha yıkıcıdır. Bu ise, insanın kıyamete daha hızlı koşması anlamına gelir.

Varsayalım, dile getirdiğimiz çekincelerin birçoğu uçuk öngörülerdir. Zira yapay zekâ, sanıldığı kadar zeki değildir. Bugün için bu itiraz doğrudur. ${ }^{22}$ Ancak insan, aklını başına alıp doğru adımlar atmazsa yapay zekâ endüstrisindeki gelişmeler tehlikeli boyutlar sergileyecek güçte görünmektedir. Mesela Mühendislik Direktörü Ray Kurzweil, şöyle bir uyarıda bulunmaktadır: Kâğıt atacı üretmek için elindeki tüm kaynakları kullanmaya programlanmış olan süper zeki bir makina, bütün insanları eritip ataş yapabilir. Sonsuza kadar kâğıt ataşı üretmek için çalışan ve üretimi optimize etmek için insana soykırımı uygulamaya başlayan bir makine gerçekten zeki midir? Açıktır ki bu zekâ, yıkıcı bir zekâdır. Demek ki, insanların faydasına olduğu düşüncesi ile üretilen bir yapay zekâ insanın sonunu da getirebilir. ${ }^{23}$ Böyle bir robotun Shackled AI'dan bir farkı olabilir mi? Shackled AI, kötülük yapmak için programlanmış ayağ 1 prangalı bir yapay zekâdır. ${ }^{24}$ Netice itibariyle insana benzeyen yapay zekâlardan doğal olarak korkmak gerekmektedir. Çünkü bu robot-insanlar, insandan daha zeki olabilirler. İnsan gibi kötülük de yapabilirler. Malum olduğu üzere, teknoloji ile buluşan insan, evreni cehenneme çevirme yarışına girmekten çekinmemektedir.

İnsandan çok daha zeki robot-insanlar üreterek denetimi onlara birakmak da doğru bir yol değildir. Burada düz bir mantık ile süper zekâdan korkmamak gerektiği ileri sürülebilir. Belki de evrenin sırlarını anlayan süper zeki robotların insan gibi evrene zarar vermeyecekleri, hatta insanların evrene zarar vermesinin önüne de geçebilecekleri hayal edilebilir. Ancak bize göre çılak zekânın beklenilen yönde tavır sergilemesi oldukça zor

\footnotetext{
20 https://www.dunyahalleri.com/barcelonada-seks-robotu-genelevi-acildi/ (07.09.2020)

${ }^{21}$ Krş. Kafalı, Hasan (2019), "Yapay Zekâ, Toplum ve Din’in Geleceği”, Ondokuz Mayıs Üniversitesi Ilahiyat Fakültesi Dergisi 46 (2), 145-172.

${ }^{22}$ Krş. PİRİM, Harun (2006), "Yapay Zeka”, Journal of Yasar University, 1(1), 92.

${ }^{23} \mathrm{https}$ ///en.wikipedia.org/wiki/How_to_Create_a_Mind (07.09.2020)

${ }^{24}$ https://khosann.com/musk-marka-karsi-yapay-zeka-ne-kadar-zeki/ (07.09.2020)
} 
görünmektedir. İfade ettiğimiz gibi, insanın ürettiği yapay zekânın gönlü söylemden ibarettir. Yapay zekâlar şuan ilkel durumda oldukları için biz bunu biliyoruz. Ama ilerde çok daha gelişmiş bir yapay zekâ için şimdi bildiklerimiz bir anlam ifade etmeyebilir. Zira içinde olduğumuz ile bildiğimiz çatışacaktır. Nihayetinde de eski bilgiler değil, bizzat yaşanan galip gelecektir.

Yapay zekânın neler yapabileceği insanlaşan makinelerden daha açık bir şekilde makineleşen insanlardan hareketle de kestirilebilir. Öyle ki, düşünen robotlardan önce insanların organik birer süper bilgisayara dönüşme ihtimali çok daha yüksek görünmektedir. İnsan beynine yerleştirilen küçük yongalar sayesinde insanlar telepatik internetle birbirlerine bağlanarak paralel işlemcili dev bir ortak zekâ oluşturabilir. Bu dev zekâ, devasa bir akla ya da akıllara da dayanabilir. Buradan bilge bir süper zekâ çıkma ihtimali vardır. Lakin biliyoruz ve yaşıyoruz ki, bilgelik insanlığın çokça ihmal ettiği bir erdemdir. Bu nedenle zeki robot-insanlardan daha çok zeki makine-insanlar endişe verici ve tehlikeli olacaklardır. ${ }^{25}$

Hâs1lı yapay zekâ henüz emekleme dönemindeki bir çocuk konumunda görünmektedir. Ama yaşına göre çok becerikli, hızlı ve zekidir. Temelde çalışma sistemi insan beyninden çok farklıdır. Yapay zekâ çalışanları, bütün güçleriyle yapay zekâ programlarını insan beynine benzetmek için çaba sarf etmektedirler. Bu, başarılabilir mi? Şimdilik meçhul. Ancak ilkece insana benzeyen yapay zekâlar üretilmiş durumdadır. Mesela bebekler gibi deneyerek, gözlemleyerek öğrenen, öğrendiği yeni verilerle programını güncelleyen; hatta gösterildiğinde öğrenebilen zeki robotlar tasarlanmış durumdadır.

Yapay zekânın ezberci zihniyetle değil, mantık yürüterek çalıştığını da görebilmekteyiz. Fakat insan zekâsının bir tür network zekâsı olup olmadığı hususunda kafamız karışık. İnsan beyninde her biri 100 nörondan oluşan 300 milyon desen tanıma birimi var. Bunlar insan beyninin ön lobunda bulunmaktadır. Yaşadıklarımız, tecrübelerimiz, öğrendiklerimiz ve anılarımız birbirleriyle özel bağlantılar kurmaktalar. Bu bağlantılar ise sinir ağlarından oluşmaktadır.

Yapay zekânın beyne benzemesi için daha çok çabaya gereksinim var. Öyle ki, insan beyni, yapay zekâ gibi veri toplayarak kayıt edilen üzerinden mantık yürütmekten çok farklı olarak çağrışımlar yaparak düşünmektedir. Çağrışıma dayalı olarak düşünen "ben" bana hâlâ meçhul görünmektedir. Ancak biz verileri toplayıp, ayrıştırıp, tasarlayan yapay bir programın "ne" olduğunu bilmekteyiz. Bildiğimiz için de ona şimdilik hükmedebiliriz. Ama yarının ne getireceğini kestirmek sağlam bir öngörü gerektirmektedir.

\footnotetext{
25 Bilim kurgu yazarı Charles Stross, "Bana göre şu anda görülen ya da gelecekte görebileceğimiz yapay zekalar tehlikeli olabilir. Ama bunun tek sebebi bu yapay zekânın hizmet ettiği insanlar olur." diyor. https://www.bbc.com/turkce/haberler/2014/12/141204_yapay_zeka_insanligin_sonu (07.09.2020)
} 


\section{Sonuç Yerine}

Bilim Kurgu Yazarı Asimov, 1942'de Robot öyküleri için üç robot yasasını yazd1. Bu yasalara göre; 1) Bir robot bir insana zarar veremez ya da bir insanın zarar görmesine seyirci kalamaz 2) Bir robot 1. kuralla çelişmediği sürece bir insanın emirlerine uymak zorundadır. 3) Bir robot 1 ve 2. kuralla çelişmediği sürece kendisinin zarar görmesine izin veremez.

Asimov, 80'den fazla robot öyküsü yazdı. Asimov'un yasaları, henüz yapay bir zekâya yüklenemedi. Gerçi “Üç Robot Yasası" Asimov’un öykülerinde de uygulanamıordu. Öyle ki, Asimov'un robotları, genelde birinin yaşamını kurtarmak için bir başkasınınkini tehlikeye atıyorlar. En sonda da ikilemde kalarak kendilerini imha ediyorlard1. ${ }^{26}$

Günümüzde yapay zekâ, Asimov'un öngördüklerinden çok daha ileriye gitti. Gittikçe insana daha çok benzese de bu benzerlik şekil ile taklitten öteye taşınamadı. Ancak insan ve insan beyni ve zihni ile karşılaştırıldığında oldukça ilkel kalmasına rağmen, bir insanın başaramadığı birçok işi, insana göre çok süratli bir şekilde yapabilmektedir. Bu durum insanlığı bir dizi teknik, ekonomik, felsefî, dinî, ahlâkî sorunla yüzleşmek zorunda bırakacak görünmektedir.

Türkiye'de yapay zekânın ne götürüp ne getireceği meselesi yeterince tartışılmamaktadır. Bu konudaki çalışmalar çok yetersizdir. Oysa Amerika, Çin, Rusya gibi büyük dünya devletleri hem yapay zekâ teknolojisine büyük yatırımlar yapmakta hem de bütün yönleriyle yapay zekâ konusu değişik mahfillerde araştırılıp incelenmektedir.

Yapay zekâ teknolojisi daha fazla ileriye götürülmeden mevcut hâliyle stilize edilip insan yaşamında etkinleşmeye başlaması bile bir dizi dinî, felsefî ve iktisadî kırılmanın yaşanmasına sebebiyet verecektir. Modern dünya bu yeni gelişmenin farkındadır. Süreci daha sancısız atlatabilmek için tedbirler almaktadır.

Türkiye'de yapay zekâ konusuna elbette tamamen duyarsız değildir. Lâkin mesele günümüz Türkiye'sinde yeterince idrak edilmiş görünmemektedir. Yapılıp edilenler daha çok bireysel ve ticarî girişimlerdir. Oysa yapay zekâ yarının teknolojisidir. Bu nedenle yapay zekâ hususunda sadece yeterli çalışmalar yapmak suretiyle hazırlananlar yarın ayakta kalabilecektir.

\section{Kaynakça}

ASIMOW, Isaac (2016), Ben Robot, çev. Ekin Odabaş, İstanbul: İthaki Yayınları, ÇAĞLAR, Ersoy (2019), Robotlar, Yapay Zeka ve Hukuk, 3. Baskı, İstanbul: On iki Levha Yayınc1lik,

\footnotetext{
${ }^{26}$ Bkz. ASİMOW, Isaac (2016), Ben Robot, çev. Ekin Odabaş, İstanbul: İthaki Yayınları, s. 15.
} 
DEMIRHAN, Ayşe; KILIÇ, Yusuf Alper; GÜLER, İnan (2010), "Tipta Yapay Zeka Uygulamaları", Yoğun Bakım Dergisi; 9(1):31-41.

DÖNMEZ, Süleyman, (2015) Emanet Ahlâkı: Türk Ahlâk Felsefesine Giriş, Adana: Karahan Kitabevi.

HARARİ, Y. Noah (2018), 21. Yüzyıl İçin 21 Ders, Türkçesi: Selin Siral, 9. Baskı İstanbul: Kollektif Kitap.

https://www.dunya.com/kose-yazisi/buyuk-firsatin-ortasindayiz-2025de-dijitalde-buyukpatlama-bekliyoruz/412943 (02.09.2020)

https://edam.org.tr/teknoloji-uzerine-diyaloglar-7-yapay-zeka/ (07.09.2020)

https://kurious.ku.edu.tr/teknolojinin-altin-cagi/ (07.09.2020)

https://www.matematiksel.org/bir-yapay-zeka-ornegi-kasparov-deep-blue-gercegi/

(07.09.2020).

https://www.cnnturk.com/teknoloji/yapay-zeka-ile-meme-kanseri-teshisi (07.01.2020).

https://www.bbc.com/turkce/haberler/2014/12/141204_yapay_zeka_insanligin_sonu

(07.09.2019)

https://edam.org.tr/teknoloji-uzerine-diyaloglar-7-yapay-zeka/ (07.09.2020)

https://kurious.ku.edu.tr/haberler/yapay-zeka-zeki-ama-onyargili/ (07.09.2020)

https://robotic.legal/telif-hakki-yasalarinin-yapay-zekanin-dolayli-onyargi-sorununu-nasilduzeltebilecegi/ (07.09.2020)

https://www.fortuneturkey.com/yapay-zekanin-onyargi-sorunu-54794 (07.09.2020)

https://khosann.com/ahlakli-robotlar-1-robotlar-etik-kararlar-alabilir-mi/ (07.09.2020)

https://www.dunyahalleri.com/barcelonada-seks-robotu-genelevi-acildi/ (07.09.2020)

https://en.wikipedia.org/wiki/How_to_Create_a_Mind (07.09.2020)

https://khosann.com/musk-marka-karsi-yapay-zeka-ne-kadar-zeki/ (07.09.2020)

https://www.bbc.com/turkce/haberler/2014/12/141204_yapay_zeka_insanligin_sonu

(07.09.202

KAYNAK ILTAR, Ekin (2019), Dijital Nesillerin Teknoloji Bağımlılığı-Teknolojïinin Etik Çıkmazlar: İnternetin Ebeveyn ve Çocuklar Üzerindeki Etkilerine İlişkin Etik Bir Inceleme, Ankara: Nobel Yayınevi,

KAFALI, Hasan (2019), "Yapay Zekâ, Toplum ve Din'in Geleceği”, Ondokuz Mayıs Üniversitesi İahiyat Fakültesi Dergisi 46(2): 145-172.

PİRIM, Harun (2006), "Yapay Zeka", Journal of Yasar University, 1(1): 81-93.

TOPAKKAYA, Arslan ve EYİBAŞ, Yağmur (2019), "Yapay Zekâ ve Etik İlişkisi", Felsefe Dünyası 70 (1): 81-99.

UYGUNOĞLU, Tayfun ve YURTCU, Şaban (2006), "Yapay Zeka Tekniklerinin İnşaat Mühendisliği Problemlerinde Kullanımı” Teknolojik Araştırmalar: YTED 1 (1): 61 - 70 


\title{
ARTIFICIAL INTELLIGENCE IN THE PHILOSOPHICAL CONTEXT AND THE 2025 SYNDROME
}

\begin{abstract}
Artificial intelligence, which emerged with the invention of the first computer about 60 years ago, is one of the most important developments of today and the future, although it is a frequently heard expression in recent years. So much so that artificial intelligence technology seems to encompass almost entirely commercial life, especially from 2025 onwards. It should not be mistaken that this siege will remain solely on a commercial scale. Many experts are talking about 2025 syndrome with the assumption that artificial intelligence will contribute to human life in many different dimensions in the coming years. On the other hand, the ideas put forward in this regard are essentially not completely unfounded. So much so that artificial intelligence is more and more like human being. In fact, he is more knowledgeable, resourceful, and fast in some subjects, especially in terms of expertise. However, this does not mean that artificial intelligence will be a great danger for humanity in the first place. Yet control is in man. It remains unclear whether machines can escape human control or control people.

The second aspect is what the artificial intelligence brings with its present state. Therefore, what problems will be caused by artificial intelligence, which will be largely in human life by 2025. So that artificial intelligence, humanity from morality, economy, science, art, philosophy, religion, law, politics; in short, it appears that it will have to deal with a number of issues that will spread to every aspect of life. In this case, the issue of what artificial intelligence will bring to humanity should be opened to discussion in many ways.
\end{abstract}

In this article, the issue of artificial intelligence is summarized in the context of both the abovementioned contexts.

In order to understand what artificial intelligence is, first of all it is necessary to understand what intelligence is. There is a closedness in the definitions of intelligence. In general, intelligence is explained by cognitive abilities. Cognitive abilities can classify patterns into an extended list, such as classification, reasoning, using conceptual models, problem solving, creativity and memory. In this context, intelligence is based on a measure and practice. The expression of artificial intelligence is predominantly based on this framework.

Artificial intelligence was first introduced by John McCarthy, a Professor at Stanford University. It is sometimes used as Machine Intelligence. The term Machine Intelligence should not be confused with "Machine Learning".

Artificial intelligence is the science and engineering of making intelligent machines, especially intelligent computer programs. Although it is about trying to understand human intelligence through computers, a similar task, it does not limit itself to methods that can only be observed biologically.

The subject of this research is not the technical sense of artificial intelligence. Therefore, little information is given about the technical aspect or mathematics of artificial intelligence in this study.

In this article, we have discussed what kind of changes in philosophical, religious and economic terms can be revealed in the future with artificial intelligence technology which has become an integral part of our lives and why we should turn to artificial intelligence.

Essentially, Artificial Intelligence is not intended to replace people, but is designed with the hope of significantly improving human talents and contributions. For this reason, it is aimed to increase the standard of human life with an augmented reality rather than loss of human in a virtual reality when artificial intelligence becomes a part of human life. However, as the artificial intelligence is realized, this goal brings with it a series of concerns. Because the field of action of artificial intelligence is shifting to a mixed reality.

When people express their fear of artificial intelligence, they often dream of out-of-control humanoid robots, like the Terminator. Sometimes, with the metaphors of the past, the concern of observing in the virtual world is carried. Although George Orwell's 1984 work is still remarkable, it is not the right dystopia for the 21st century. What we have to fear most is not what artificial intelligence will do to us on its own, but how people with power can use it in a new, sometimes hidden, uncertain and unexpected way to control and manipulate us. Most of the technology that threatens our independence and reputation in the near future is being developed by companies that collect and sell our data and attention to advertisers and the like. These are done through social platforms such as Facebook, Google, Amazon, Alibaba, Apple, Tesla ...

Although artificial intelligence seems to be a new technology after internet advertising, the situation is different. We are facing a whole new process. We are on our way to a completely different world. It accelerates our understanding in the fields of research and investigation. However, these developments bring serious problems and risks.

In a virtual world with the help of artificial intelligence, persuasion methods can be created to reach billions. Artificial intelligence can understand each person by targeting. It can detect people's weakest points. The information obtained can even be sent to the personal phone screen we are using. Direct people by direct supervision. Such developments will start to cause great moral problems.

The problems that may arise with the spread of artificial intelligence can be brought to the ground of discussion in roughly two different contexts. 
The first is what artificial intelligence can afford more than what it is. This aspect of the issue will lead the researcher to a series of fantastic or fictional analyzes, either positive or negative. In fact, the real reason why artificial intelligence technology, which actually remains at a very primitive level when compared with the human mind, is being revived as highly functional, human-like robots that take over the world in minds, is also open-ended.

Keywords: Artificial intelligence, morality, intelligent robot, mind, brain. 